\title{
Two decades of psychiatry in Zimbabwe: 1964-1984
}

\author{
Terry Buchan, Head of Department of Psychiatry, Swan District Hospital, Viveash, \\ Western Australia
}

The first Pan African Conference in 1961 made a number of recommendations to guide the development of psychiatric services in emergent African countries. The purpose of this paper is to show that the application of these recommendations, admittedly serendipitously at times, led to a considerable measure of success in Zimbabwe.

The population of the country, about 7.5 million at independence in 1980, is divided by language into two major groups, the Mashona and the Matabele. There were significant differences in the services which developed in Matabeleland as compared with Mashonaland.

\section{Experience in Matabeleland}

During the early 1960s, Ingutsheni* Hospital Bulawayo comprised some 763 beds and the annual turnover for the six years 1960-1965 was about 8001000 patients and with 1252 patients crammed into 763 beds, it was obvious that there was gross overcrowding. An important contributory factor in the development of the unacceptable level of overcrowding was the admission of many patients from Mashonaland via the holding unit in Harare, some $400 \mathrm{~km}$ distant from Bulawayo. Accordingly the following means for controlling admissions to Ingutsheni were implemented in 1966:

(a) no further admissions to be accepted from Mashonaland

(b) a waiting list to be introduced so that patients could only be admitted as beds became vacant

(c) a vigorous discharge policy to be pursued.

These measures proved to be effective and by the end of 1969 the hospital population had fallen to 969 . Another important factor in the reduction in the length of stay.

The bald figures, however, concealed the fact that the overcrowding in the wards for black African patients, who were in the majority, was worse than for the other racial groups.

Accordingly, a survey was undertaken of this group of patients for the three year period 1969-71 inclusive (Buchan \& Baker, 1974). The survey was

"From an Ndebele word meaning "the place of blankets". Locally the hospital was invariably referred to as Inhlanyeni - "The place of mad people". divided into two parts: a survey of patients in residence as at 31 December, and a survey of cases discharged during each of the three years.

Principal diagnostic categories among the residents were schizophrenia (43.0\%), retarded development (with or without epilepsy) $(17.5 \%)$ and epilepsy $(20.2 \%)$. The categories for neurotic illness (depression, anxiety states, dissociated states) accounted for only a handful of patients.

Principal diagnostic categories among discharged patients, averaged for 1970 and 1971, were: schizophrenia (47.0\%), depression (6.4\%), acute brain syndrome $(9.8 \%)$, chronic brain syndrome $(5.1 \%)$ and epilepsy $(17.6 \%)$.

Two significant differences from mental hospital populations in Britain were apparent. Males outnumbered females by more than two to one in all age groups and there was no build-up of geriatric patients. The preponderance of male patients was never adequately explained, but it may be that aggressive and/or antisocial behaviours are largely a male prerogative, thereby acting as selective factors in admission. The comparatively small population of elderly patients may have been a reflection of the population structure. At the time of the 1969 census, $49.5 \%$ of the population was under 15 years of age.

Inasmuch as $80 \%$ of the hospital residents were long-stay and $40 \%$ were schizophrenic, our problems were similar to those found in Britain. The comparatively high proportion of patients who were epileptic may have been accounted for by aetiological factors such as brain injury, cysticercosis and syphilis (Rachman, 1970). A comparatively high proportion of residents were intellectually handicapped $(17.5 \%)$ but few were discharged (1.6\%), which suggested a hard core of such patients who could not be reintegrated into the community. Finally, at least onethird of all discharges had been admitted more than once.

With these considerations in mind, the following recommendations were framed:

(a) because community care is not a cheap alternative to hospital care the retention of a psychiatric hospital centred service to be accepted policy

(b) the quality of life for in-patients to be improved

(c) an after-care service to be introduced, aimed primarily at reducing the re-admission rates for schizophrenic and epileptic patients 
(d) consideration to be given to the development of alternative community based facilities for the mentally handicapped.

The implementation of these recommendations proceeded as follows:

(a) Improving the quality of life for in-patients was tackled in three ways:

(i) Separate admission units were established with 60 male and 24 female beds, permitting a more rational distribution of staff and resources.

(ii) The 'empty ward' principle was adopted as policy. During the day it was expected that both patients and staff would be out of the ward, engaging in activities of one sort or another.

Over a period of years there was considerable expansion of occupational and recreational facilities.

(iii) The quality of nursing care was improved by the introduction of an 18 months post basic training course for psychiatric nurses, ensuring that there would be an adequate number of trained staff.

(b) Development of the follow-up service started in June 1972 and review clinics were established in four urban and 21 rural health centres in central Matebeleland.

To assess the effectiveness of this service, a study was made of its first complete year of operation (1973) (Buchan \& Hudson, 1975).

The 472 Black African patients admitted to Ingutsheni Hospital during 1972 were followed up until the end of 1973, that is for one to two years. Only 14 remained in hospital at the end of 1973. Fifty patients $(13.5 \%)$ were readmitted; three were readmitted twice and one was readmitted three times but there was no evidence of a 'revolving door' pattern.

Three simple measures of clinic effectiveness were chosen:

the number of patients who never attended

the number of patients with $100 \%$ attendance records

the number of patients still under treatment at the end of

1973.

On these measures, Antelope Mine emerged as the most effective rural clinic, Pelandaba the most effective urban clinic. These two were studied in more detail in an attempt to identify successful management strategies and it seemed fair to conclude that follow up services could make significant contributions to psychiatric management in the following ways:

By providing back-up services to District Medical Officers, many disturbed patients could be dealt with at a local level without special facilities and without recourse to mental hospital admissions. In this aspect the services clearly exceeded the original brief.

Significant contributions could be made to the management of schizophrenic and epileptic patients although a direct effect on readmission rates could not be demonstrated.

By providing services close to the community, much better co-operation could be obtained from the patients. (c) The Bulawayo Mental Health Association accepted a community centre for retarded children as a project in January 1971 , and Sibantubanye* Day Centre was officially opened on 8 February 1975. Between April and August 197520 children were admitted to the centre, usually by referral from a paediatrician, and training programmes were developed.

\section{Experience in Mashonaland}

After 1966, when patients were no longer transferred to Matabeleland, there was a considerable increase in the strain placed upon the resources in Mashonaland. In response to this increased load, a standard 60 bed ward block was added to the holding unit in 1968 , increasing the total number of beds to 90 .

The annual admission rate increased steadily to reach 1,391 in 1977, but levelled in 1978; this was attributed to the introduction of a follow-up service along the same lines as Matabeleland and a $24 \%$ increase in out-patient work.

Notwithstanding the apparent improvement, the bald figures concealed a number of highly unsatisfactory features:

(a) Gross overcrowding: The 90 bed unit contained a daily average of 126 patients ( $139 \%$ occupancy), a situation which had not changed significantly since 1970 .

(b) Chronicity: The average number of days each case spent in hospital (31.8) concealed the problem of chronicity, which had two guises:

(i) Prolonged admission: The cases admitted informally stayed an average of only 13 days in hospital whereas cases admitted formally under certificates stayed an average of 131 days, i.e. $14.6 \%$ of admissions accounted for $62 \%$ of patient days.

(ii) Recurrent admissions: 133 patients were admitted two to four times during the year.

In order to provide a basis for rational planning, a survey was undertaken of 173 consecutive admissions under the care of a single clinician (TB) who made all the initial assessments and provisional diagnoses within 24 hours of admission (Buchan et al, 1981).

A number of significant findings emerged from the survey:

(a) Country of origin: Twenty-seven cases $(15.6 \%)$ were born outside Zimbabwe.

(b) Sex and marital status: The male:female ratio (2.3:1) was comparable with Matabeleland.

(c) Age and employment status: The proportions were very similar to those found in Matabeleland in 1970-71. Geriatric admissions constituted only a minor problem.

Most of the cases fell into the category of young adult but only 41 of the 173 cases $(23.7 \%)$ were in

("Sibantubanye is from a Sindebele word meaning literally, "We are the same" but there are nuances of kinship and common heritage). 
regular employment. Only eight cases were peasant farmers which suggested that we were dealing with a largely urban population.

(d) Clinical presentation: Most cases were floridly disturbed. Nevertheless, $76.5 \%$ were rated as quiet and co-operative within 24 hours, indicating that the majority will settle on a simple regimen of medication administered by nursing staff.

(e) Diagnostic categories: The major categories were schizophrenia $(38.7 \%)$ and acute brain syndrome (28.9\%); epilepsy accounted for comparatively few $(6.9 \%)$.

Alcohol related problems accounted for $23.1 \%$.

(f) Outcome: The cases were followed up for at least six months after admission, when 162 cases $(93.6 \%)$ had been discharged in remission, $115(66.5 \%)$ within one month.

The apparently high recovery and discharge rates concealed a number of highly unsatisfactory features in the practice.

(a) The short duration of stay meant that some were inadequately assessed.

(b) There was a small group of chronic patients who were not suitably managed in an acute unit.

(b) In all, $21.9 \%$ of cases had been previously admitted at least twice, or three times in all. In many cases we were doing no more than 'recycling' our chronic patients.

As a result of this study two principal recommendations were made:

(1) The management of psychiatric patients in primary care facilities should be extensively developed with three objectives in mind:

(a) The prevention of admissions:

If the patient can be managed close to home, inappropriate admission and serious injury to family and friends might be avoided. It was shown that most homicides by the insane in Zimbabwe occurred in rural as opposed to urban areas. The majority of patients suffered from potentially treatable disorders and they gave clear warning of being disturbed prior to the crime (Buchan \& Sparling, 1985).

(b) The prevention of re-admissions:

(c) The management of emotional disorders: Several studies have emphasised the significance of psychiatric morbidity in primary health care facilities in developing countries. Such evidence as was available in Zimbabwe suggested that a similar situation existed.
To implement these recommendations it was proposed that small in-patient units should be opened in District General Hospitals. Each unit was to have one bed per 10-15,000 adult population in its catchment area and was intended to serve as the focus for the organisation of psychiatric services.

To meet the manpower implications the Department of Psychiatry at the University of Zimbabwe introduced new courses, including a 12 month postgraduate medical course (leading to a Diploma in Psychiatric Health), to equip District Medical Officers to take charge of the small in-patient units. The first candidate graduated in 1983.

(2) A community based facility should be developed with the objective of rehabilitating long-term patients into the community.

With the assistance of a voluntary organisation the *Tariro Centre was opened on 17 December 1981 providing accommodation for 18 patients, 12 female and six male.

During the first six months of operation, 24 patients, six male and 18 female, were taken into the programme and 11 patients left the centre.

A number of factors impeding patients' reintegration into the community were identified: patients coming from another country or remote rural areas; family rejection of patients with prolonged or recurrent illnesses; a diagnosis of subnormality.

\section{References}

Buchan, T. \& BAKer, A. P. (1974) Psychiatric services in Matabeleland: A comparison with services existing in developed countries. South African Medical Journal, 48, 925-930.

- \& Hudson, G. (1975) Psychiatric follow-up services in Matabeleland. South African Medical Journal, 49, 21-26.

-, Nyamuswa, R. L. \& FUTter, G. E. (1981) Community psychiatric services in Mashonaland, Zimbabwe. Central African Journal of Medicine, 27, 111-115.

- \& SPARLING, P. (1985) The management of dangerous patients in Zimbabwe. In Aggression and Dangerousness (eds. D. P. Farington \& T. Gunn). Bristol: John Wiley, 241-259.

RaCHMan, I. (1970) Epilepsy in African hospital practice. Central African Journal of Medicine, 8, 201-204.

(A full list of references is available from the author)

"From a Shona word meaning "hopeful expectation". 